\title{
"Ele mudou a maneira como eu enxergava a Matemática!": a entrevista como um caminho para a prática pedagógica
}

\author{
Cristiane Coppe de Oliveira \\ Flávia de Fatima Santos Silva
}

\begin{abstract}
Resumo: 0 presente artigo compõe-se acerca da elaboração do Caderno Dirigido, inspirado pela obra Didática da Matemática de Júlio César de Mello e Souza, o Malba Tahan (1895 - 1974). Em tal proposta, de abordagem qualitativa, utiliza-se como recurso metodológico para a prática docente no Ensino Fundamental, o instrumento entrevista, realizada com o educador matemático e ex-aluno de Malba Tahan, Sergio Lorenzato. Após a análise da entrevista, buscou-se estabelecer um diálogo passado-presente entre o discurso de Malba Tahan e as falas do depoente quando foi seu aluno. 0 tema centrou-se no conhecimento do Caderno Dirigido e tal movimento possibilita a reflexão de que a História da Educação Matemática pode contribuir para criar cenários de investigação para a prática em sala de aula.
\end{abstract}

Palavras-chave: Malba Tahan. Caderno Dirigido. Sergio Lorenzato.

\section{"It changed the way i saw Math!": the interview as a path to pedagogical practice}

\begin{abstract}
This article is about the elaboration of the Directed Notebook, inspired by the Didactics of Mathematics by Júlio César de Mello e Souza, aka Malba Tahan (1895 - 1974). In this proposal, a qualitative approach was used as a methodological resource for teaching practices in elementary education. The interview instrument was carried out with a mathematical educator and former student of Malba Tahan, Sergio Lorenzato. After analyzing the interview data, we sought to establish a past-present dialogue

Cristiane Coppe de Oliveira Doutora em Educação (USP).

Professora do Programa de PósGraduação em Ensino de Ciências e

between Malba Tahan's speech and the statements of the deponent when he was his student. The theme focused on the knowledge of the directed notebook and this movement allows the reflection that the history of mathematics education can contribute to create research scenarios for the practice in the classroom.
\end{abstract}

Matemática da Universidade Federal

de Uberlândia (UFU). Professora colaboradora do Programa de PósGraduação em Educação da Universidade de São Paulo (USP). Minas Gerais, Brasil. $\triangle$ coppedeoliveira@gmail.com

Flávia de Fatima Santos Silva Mestra em Ensino de Ciências e Matemática pela Universidade Federal de Uberlândia (UFU). Professora de Matemática na rede particular em São Paulo. São Paulo, Brasil. $\bowtie$ math.flavia@gmail.com

Recebido em 20/02/2019 Aceito em 30/03/2019

Publicado em 01/09/2019
Keywords: Malba Tahan. Notebook Directed. Sergio Lorenzato.

\section{"Él cambió la forma en que yo veía las Matemáticas!": la entrevista como un camino para la práctica pedagógica}

Resumen: El presente artículo se compone de la elaboración del Cuaderno Dirigido, inspirado por la obra Didáctica de la Matemática de Julio César de Mello y Souza, el Malba Tahan (1895-1974). En esta propuesta, de abordaje cualitativo, se utiliza como recurso metodológico para la práctica docente en la Enseñanza Fundamental, el instrumento entrevista, realizada con el educador matemático y ex alumno de Malba Tahan, Sergio Lorenzato. Después del análisis de la entrevista, se buscó establecer un diálogo pasado-presente entre el discurso de Malba Tahan y las palabras del depoente cuando fue su alumno. El tema se centró en el conocimiento del Cuaderno Dirigido y tal movimiento posibilita la reflexión de que la Historia de la Educación Matemática puede contribuir a crear escenarios de investigación para la práctica en el aula.

Palabras clave: Malba Tahan. Cuaderno Dirigido. Sergio Lorenzato. 


\title{
1 Primeiras aproximações
}

Este artigo origina-se de uma pesquisa de mestrado, concluída em 2018. O estudo teve como objetivo analisar os processos de elaboração do Caderno Dirigido, que foram realizados com inspiração pela obra Didática da Matemática, de Júlio César de Mello e Souza, o Malba Tahan (1895 - 1974), e após a análise da entrevista realizada por seu ex-aluno, o professor Sergio Lorenzato. Buscou-se estabelecer um diálogo passado-presente entre o discurso de Malba Tahan e as falas do depoente para possibilidade de uma prática em sala de aula com alunos do Ensino Fundamental de uma escola particular na cidade de Guarulhos, em São Paulo.

A escolha pelo Caderno Dirigido, apontado como um recurso didático por Malba Tahan na obra Didática da Matemática, se deu pelo fato de investigar se a utilização desse instrumento pode contribuir para os processos de ensino e de aprendizagem da Matemática, especificamente para o trabalho com conceitos geométricos. A escolha pela Geometria ocasionou-se pela aproximação com o termo Geometrismo, apontado por Tahan (1961a, p. 113):

\begin{abstract}
Alguns matemáticos, obcecados pela mania de complicar e obscurecer o ensino, a granizar teorias mirabolantes, conseguem impingir algebrismo em Geometria. Essa face especial do algebrismo é denominada Geometrismo. Ciência simples, de rara perfeição lógica, de incomparável beleza, a Geometria recebe, também, o largo implemento do entulho algebrista. Cumpre, também, ao professor consciencioso, bem orientado sobre os objetivos da Matemática, não torturar os seus alunos com teoremas geométricos que exijam demonstrações trabalhosas, ou longos raciocínios cheios de sutilezas.
\end{abstract}

Já o título desse artigo, em que se utilizou a frase Ele mudou a maneira como eu enxergava a Matemática, compreende parte do depoimento do educador Sergio Lorenzato, no sentido de enaltecer a entrevista como um elemento de relevância para as escolhas metodológicas que se fazem necessárias em processos investigativos, tomando como exemplo a aproximação do objeto da pesquisa, Caderno Dirigido, a partir da oralidade.

$\mathrm{O}$ depoente foi escolhido pelo fato de ter sido aluno do curso oferecido por Malba Tahan no âmbito da Campanha de Aperfeiçoamento e Difusão do Ensino Secundário (CADES), acerca da Didática da Matemática, ministrado em São Carlos no ano de 1958 e pelo fato de ter vivenciado, enquanto aluno, a experiência com o caderno de classe - Caderno Dirigido, utilizado por Malba Tahan como um recurso didático em que o aluno elaborava, autonomamente, suas anotações a partir do conteúdo trabalhado.

Durante o curso de formação da CADES, o Caderno Dirigido foi utilizado como um objeto de estudos, escrita e desenvolvimento de conhecimentos matemáticos oferecendo para o grupo 
autonomia, possibilidade de expressar sua criatividade de maneira crítica e dialógica. A aproximação com o Caderno Dirigido se deu por meio da obra Didática da Matemática e, ao longo do processo investigativo, aprimorou-se com o depoimento do professor Sergio Lorenzato e a suas memórias acerca desse Caderno.

Após a imersão e análise do depoimento gravado em áudio e vídeo da entrevista com 0 professor Sergio Lorenzato, realizada dia 13 de maio de 2017, na Universidade Cidade de São Paulo, por ocasião da realização do XIII Encontro Paulista de Educação Matemática (EPEM), elencou-se elementos que subsidiaram a investigação, organizando fragmentos da entrevista em categorias. Essas categorias foram organizadas em três cenários ${ }^{1}$, subdivididos em doze encontros em que se possibilitou organizar um teatro com alunos do Ensino Fundamental de uma escola particular na cidade de Guarulhos (SP).

Quadro 1: Cronograma de encontros

\begin{tabular}{|c|c|c|}
\hline Cronograma de Encontros & Categorias da Pesquisa & Cenas da Investigação \\
\hline \multicolumn{3}{|l|}{$1^{0}-6$ set. 2017} \\
\hline $2^{0}-20$ set. 2017 & \multirow{2}{*}{$\begin{array}{c}\text { Primeira categoria } \\
\text { Aproximação afetiva e } \\
\text { familiarização com a escrita }\end{array}$} & \multirow{2}{*}{$\begin{array}{c}\text { Descaracterização dos } \\
\text { ambientes de sala de aula }\end{array}$} \\
\hline $3^{0}-27$ set. 2017 & & \\
\hline $4^{0}-4$ out. 2017 & \multirow{4}{*}{$\begin{array}{l}\text { Segunda categoria } \\
\text { Conversas, valorização da } \\
\text { autonomia e criatividade }\end{array}$} & \multirow{4}{*}{$\begin{array}{l}\text { Construção dos cenários } \\
\text { fora da sala de aula a partir } \\
\text { da literatura de Malba Tahar }\end{array}$} \\
\hline $5^{\circ}-6$ out. 2017 & & \\
\hline $6^{0}-11$ out. 2017 & & \\
\hline $7^{0}-18$ out. 2017 & & \\
\hline $8^{\circ}-24$ out. 2017 & \multirow{4}{*}{$\begin{array}{c}\text { Terceira categoria } \\
\text { Escolhas e caminhos a partir } \\
\text { dos discursos }\end{array}$} & \multirow{4}{*}{$\begin{array}{c}\text { Autonomia, reflexão, } \\
\text { dialogicidade, criatividade e } \\
\text { afetividade }\end{array}$} \\
\hline $9^{0}-25$ out. 2017 & & \\
\hline $10^{\circ}-26$ out. 2017 & & \\
\hline $11^{\circ}-1$ nov. 2017 & & \\
\hline $12^{\circ}-8$ nov. 2017 & & Confraternização \\
\hline
\end{tabular}

Fonte: Elaboração das Autoras

\footnotetext{
1 Entende-se por "cenário" o lugar em que decorre uma ação ou parte dela, onde o conjunto de elementos visuais compõe o espaço onde se apresenta um espetáculo. Na investigação os cenários configuraram-se como os momentos experienciados e criados pelos alunos em sala de aula (ambientes de aprendizagem), definidos por categorias estabelecidas de acordo com a análise do depoimento do educador matemático Sergio Lorenzato.
} 
A cada encontro, as especificidades dos alunos possibilitaram características singulares ao produto, subdivididas em três categorias do depoente ao Malba Tahan: aproximação afetiva e familiarização com a escrita; conversas, valorização da autonomia e criatividade; escolhas e caminhos a partir dos discursos. Pode-se compreender esses caminhos que podem ser mais bem representadas no Quadro 1.

Como a natureza da pesquisa compunha-se em um mestrado profissional, pretendia-se elaborar, compor - juntamente com os alunos - e apresentar uma peça teatral sobre Malba Tahan que propiciasse ao grupo criatividade e desenvolvimento intelectual no que tange aos aspectos da História da Educação Matemática. Tal desafio proporcionou, durante 0 desenvolvimento do projeto, o movimento passado-presente articulando saberes entre Malba Tahan, Sergio Lorenzato e os alunos do Ensino Fundamental participantes da pesquisa.

A metodologia utilizada, privilegiando a entrevista para definir a própria trajetória da investigação, permitiu a reflexão de que o entrevistado atuou como um agente histórico, o qual propiciou um movimento estrutural à pesquisadora e potencializou os estudos das fontes mais relevantes (ABREU, 2017). Tal evidência, apontou como tarefa a escrita deste artigo, destacando a entrevista como um instrumento potencializador da pesquisa, possibilitando uma aproximação mais direta e imediata às fontes históricas e contribuindo para o aprofundamento dos temas de investigação.

Diante do exposto, pretende-se explorar o instrumento metodológico entrevista, como um elemento fundamental para delinear os caminhos da pesquisa, exemplificando o processo realizado ao longo da investigação de mestrado da segunda autora.

\section{História da Educação Matemática e a entrevista}

A História da Matemática caminha em uma perspectiva que oferece algumas possibilidades para a sala de aula. Nesse sentido, de igual modo a História da Educação Matemática nos remete à compreensão de práticas docentes do passado, que ajuda na compreensão de práticas atuais. No contexto da História da Educação Matemática, a História da Matemática escolar se faz presente onde os aspectos decorrentes passam a se tornar documentos e objetos de estudo e pesquisa intrínsecos à prática do professor. Esses aspectos podem ser registros de diários de classe, narrativas de professores e outro que tem suma relevância para nossa pesquisa: o caderno de alunos. A perspectiva sobre a História da Educação Matemática é bem explicitada por Garnica e Souza (2012, p. 43), ao considerar que 
A História da Matemática escolar pode ser vista como uma parte do que chamamos de História da Educação Matemática. A História da Matemática escolar está diretamente interessada em como, na escola, a matemática vem se articulando, vem sendo ensinada no correr dos tempos. Esse estudo, obviamente, envolve fatores que escapam à sala de aula e por isso não é tão nítida a distância entre a História da Educação Matemática e a História da Matemática escolar. Entretanto, se considerarmos que a matemática que circula nos domínios da escola não é necessariamente aquela matemática produzida pelos matemáticos (ou seja, se considerarmos que a matemática escolar não é uma transposição ou uma simplificação ou descaracterização da matemática desenvolvida pelos matemáticos, mas uma matemática própria; ou, ainda, se conseguirmos caracterizar a matemática profissional em relação à matemática que vai à escola, ou, segundo alguns pesquisadores, a matemática do matemático daquela matemática do professor de matemática, ou, mais ainda, se considerarmos que a educação matemática volta-se a compreender as instâncias e o contexto em que ocorrem o ensino e a aprendizagem de matemática, e que aprender e ensinar matemática não é algo que ocorre apenas na escola), estaremos já estabelecendo uma relação entre História da Matemática, História da Matemática escolar e História da Educação Matemática.

Outras possibilidades de interação emergem em busca de promover uma aprendizagem exitosa que nos situa sobre a História da Educação Matemática. Para o contexto da pesquisa de dissertação concluída em 2018, encontrou-se a possibilidade por meio do diálogo proporcionado pela entrevista.

Muitas pesquisas em Educação Matemática têm-se utilizado da entrevista como principal instrumento de coleta de dados. De acordo com Richardson et al. (1985) apud Fiorentini e Lorenzato (2006, p. 120),

a entrevista é, nas ciências sociais, o procedimento mais usual no trabalho de campo. Trata-se de uma conversa a dois com propósitos bem definidos. Etimologicamente, a palavra entrevista é construída a partir de duas palavras entre (lugar ou espaço que separa duas pessoas ou coisas) e vista (ato de ver, perceber). Ou seja, a entrevista é uma comunicação bilateral e significa o "ato de perceber realizado entre duas pessoas".

Amado (2013) considera a entrevista como um dos mais poderosos meios para se chegar ao entendimento dos seres humanos e para a obtenção de informações nos mais diversos campos. $\mathrm{O}$ autor entende que

em termos gerais, pode dizer-se que uma entrevista é:

- um meio potencial de transferência de uma pessoa (o informante), para outra (o entrevistador) de pura informação; pois um método, por excelência, de recolha de informação;

- uma transação que possui inevitáveis pressupostos que devem ser reconhecidos e controlados a partir de um bom plano de investigação. Nestes pressupostos contam-se: emoções, necessidades inconscientes, influências interpessoais;

- uma conversa intencional orientada por objetivos precisos. De entre esses objetivos sublinhe-se que a entrevista é o método adequado para "análise do sentido que os atores dão às suas práticas e aos acontecimentos com os quais se veem 
confrontados: os seus sistemas de valores, as suas referências normativas, as suas interpretações de situações conflituosas ou não, as leituras que fazem das próprias experiências, etc". (Quivy e Campenhout, 1998 apud AMADO, 2013, p. 207)

A partir dessas considerações e, mais especificamente, no sentido de entender a entrevista como leituras que se fazem das próprias experiências no contexto da pesquisa desenvolvida, viu-se a possibilidade de aproximação do Caderno Dirigido apontado por Malba Tahan, por meio da entrevista com o educador Sergio Lorenzato.

O professor Sergio Lorenzato, tal como apontou-se anteriormente, foi aluno de Malba Tahan em 1958 na cidade de São Carlos em um curso acerca da Didática da Matemática. Lorenzato confeccionou o seu próprio Caderno Dirigido com a orientação de Malba Tahan, e 0 guarda em seu acervo pessoal, como também destaca Oliveira (2001, p. 80-81):

\begin{abstract}
Segundo o educador matemático Prof. Sergio Lorenzato, no curso de didática de matemática e didática geral, Malba Tahan queria que os alunos fizessem um caderno controlado dirigido (o professor ainda possui esse caderno, com uma dedicatória de Malba Tahan), onde se colocaria questões apresentadas no quadro, incluiria as provas e as sabatinas. "Era uma 'colcha de retalhos' sobre coisas interessantes que poderiam ser utilizadas na sala de aula", afirma o Prof. Lorenzato. A obra Didática da Matemática expressa idéias de um educador e, por que não dizer, de um educador matemático, que queria que suas concepções auxiliassem os professores na difícil tarefa de "ensinar" e iluminassem os caminhos do ensino da matemática, tornando-a agradável, divertida e curiosa.
\end{abstract}

No Quadro 2, apresenta-se algumas informações acerca do depoente, a fim de situar o leitor sobre as perspectivas do entrevistado:

Quadro 2: Entrevistado selecionado

\title{
Entrevistado: Prof. Dr. Sergio Apparecido Lorenzato
}

Descrição: Licenciado em Matemática pela Faculdade de Filosofia Ciências e Letras de Rio Claro (1965), Mestre em Educação pela Universidade de Brasília (1968) e Doutor em Ciências Humanas pela Universidade Estadual de Campinas (1976). É professor colaborador da Universidade Estadual de Campinas. Tem experiência na área de Educação, com ênfase em Educação Matemática, atuando principalmente nos seguintes temas: Educação Matemática, Metodologia do ensino da Matemática, aprendizagem matemática, educação infantil e formação de professores de Matemática.

Fonte: Plataforma Lattes, Disponivel em http://lattes.cnpq.br/0433106167291528; acesso em fev. 2018

Poder dialogar, ouvir e se conectar com a experiência vivenciada pelo professor Sergio Lorenzato, por meio da entrevista, surgiu como um elemento que transcendia as expectativas iniciais da trajetória da pesquisa.

Durante a entrevista, elaborou-se um roteiro semiestruturado, em que as questões se tornaram ponto de partida para a conversa. Ao mesmo tempo, as questões eram abertas às 
intervenções na mediação entre pesquisadora e depoente, tornando possível considerar as opiniões do entrevistado, acerca do tema da pesquisa. Compôs-se, então, um roteiro com seis questões, considerando a perspectiva de Amado (2013, p. 208-209I) de que

as questões derivam de um plano prévio, um guião onde se define e regista, numa ordem lógica para o entrevistador, o essencial do que se pretende obter, embora, na interação se venha a dar uma grande liberdade de resposta ao entrevistado. A bibliografia (Gilham, 2000; Kavle, 1996; Bogdam e Biklen, 1994; Ghiglione e Matalon, 1992; Quivy e Campenhoudt, 1998; Ludke e André, 1986) aponta a entrevista semiestruturada (ou semidiretiva) como um dos principais instrumentos da pesquisa de natureza qualitativa, sobretudo pelo fato de não haver uma imposição rígida das questões, o que permite ao entrevistado discorrer sobre o tema proposto "respeitando os seus quadros de referência", salientando o que para ele for mais relevante, com as palavras e a ordem que mais the convier, e possibilitando a captação imediata e corrente das informações desejadas.

As questões orientadoras (Quadro 3), ou roteiro, foram elaboradas no sentido de compreender a trajetória pessoal e acadêmica do professor Sergio Lorenzato e descrever quais ideias e concepções provenientes do discurso de Malba Tahan influenciaram sua prática. Além de saber, com maior aprofundamento, como foi o processo de elaboração do Caderno Dirigido em 1958, mantido em seu acervo pessoal.

Algumas recomendações foram seguidas para que o procedimento da entrevista fosse adequado, como orientam Fiorentini e Lorenzato (2006, p. 122-123):

Antes de iniciar o processo de entrevista, o entrevistador deve explicar o objeto e a natureza do trabalho, esclarecendo por que ele foi escolhido para a entrevista.

Assegurar o anonimato do entrevistado e o sigilo dos depoimentos, garantindo que os mesmos serão utilizados somente para a finalidade da investigação.

O entrevistador deve solicitar a autorização para gravar (em áudio e vídeo) a entrevista, assegurando, depois, que a transcrição será lida, revisada e autorizada pelo entrevistado.

Escolher, para a entrevista, um lugar apropriado e tranquilo que favoreça um diálogo profundo, esclarecendo que o entrevistado tem o direito de não responder a todas as perguntas, podendo, inclusive interromper a entrevista.

Por isso, o entrevistador não deve discutir sua opinião ou seus pontos de vista, nem mostrar surpresa ou desaprovação e, menos ainda, avaliar negativamente sua fala. Ao contrário, deve demonstrar grande interesse no que o entrevistado diz ou narra.

Recomenda-se que o entrevistador não interrompa o curso do pensamento do entrevistado. Não apresse o entrevistado e dê o tempo necessário para que conclua seu depoimento. Evite, também, perguntas diretas, como por exemplo: "qual a tua concepção de currículo?". Perguntas, como essa, induzem a respostas superficiais e estereotipadas. A concepção de currículo do entrevistado resulta da análise e interpretação do pesquisador sobre o discurso do entrevistado. 
Após uma conversa, considerando-se os elementos da citação anterior, delineou-se 0 percurso da pesquisa, fazendo com que o depoimento de Lorenzato, orientadas pelas ideias de Malba Tahan, direcionassem a investigação.

\section{Quadro 3: Questões orientadoras}

1. Fale um pouco sobre a ocasião, motivação/razão em que foi aluno de Malba Tahan.

2. O senhor considera que a motivação/razão que o levou a ser aluno de Malba Tahan contribuiu para o seu futuro como educador matemático?

3. É de nosso conhecimento que o senhor tem um Caderno Dirigido da época em que fez um curso com Malba Tahan. O senhor pode contar o que esta prática representou para o senhor na época? 0 que representa hoje?

4. Como educador matemático, o senhor já utilizou em sua prática docente o Caderno Dirigido ou algum elemento semelhante com inspiração em Malba Tahan?

5. Na ocasião em que o senhor foi aluno de Malba Tahan, ele trabalhou com os termos "Algebrismo" ou "Geometrismo" em sala de aula? Se sim, o que o senhor pode dizer sobre esses termos?

6. Malba Tahan aponta que o uso do Caderno Dirigido proporciona uma relação afetiva e dialogada entre o professor e 0 aluno. $O$ senhor acredita nessa perspectiva?

Fonte: Elaboração das Autoras

Outro fato importante a se considerar é a possibilidade de exploração que emerge em um registro oral, tal como defende Abreu (2017, p. 51):

Pensando em suas vantagens em relação a outras fontes históricas disponíveis, temos, primeiramente, o benefício de poder questionar 0 entrevistado sobre qualquer tópico desejado. Ao trabalhar com fontes escritas de outro momento, o pesquisador fica preso a um processo de interlocução que, muitas vezes é alheio às suas necessidades. Ao colocar o entrevistado como agente histórico, essa metodologia de trabalho também dinamiza a participação do pesquisador, no sentido de lhe possibilitar buscar em sua fonte as evidências que considera mais relevantes para a reconstrução que deseja executar, as quais facilitam, em princípio, o alcance dos objetivos estabelecidos.

Os objetivos da entrevista ressaltariam para além da pergunta norteadora da pesquisa, envolvendo elementos considerados por Amado (2013), tais como "emoções, necessidades inconscientes e influências interpessoais", visto que poderia se estabelecer uma perspectiva afetiva e dialógica entre o depoente e a entrevistadora, ao compor o cenário de encantamento sobre a Matemática, pelo fato do entrevistado ter convivido com Malba Tahan. A aproximação de Lorenzato e Malba Tahan foi explorada na pesquisa de Oliveira (2001, p. 17):

Segundo Lorenzato, Malba Tahan ensinava Matemática com arte, conhecimento e sabedoria, propunha novas alternativas para melhorar o ensino-aprendizagem de matemática e divulgava suas idéias numa época em que prevalecia fortemente 0 dogma de que "para ser um bom professor de Matemática basta conhecer Matemática" 
e também campeavam sem questionamentos, inúmeros mitos tais como "Matemática é difícil", "só os inteligentes aprendem Matemática", "bom professor é o que reprova muitos alunos", "vou escolher uma profissão que não use Matemática.

Além das orientações e cuidados com o processo dialógico, no que se refere ao caráter ético da pesquisa, após a gravação do depoimento em áudio e vídeo e procedimento de transcrição, o material foi enviado ao entrevistado para que possíveis correções ou intervenções na escrita fossem realizadas. Após o retorno do depoente, iniciou-se um processo de reflexão sobre o material, para delinear as escolhas e os caminhos da pesquisa.

\title{
3 Revelando categorias a partir da entrevista
}

O momento pós-transcrição da entrevista possibilitou trazer uma aproximação entre 0 discurso do depoente e o discurso de Malba Tahan, para direcionar os caminhos que seriam seguidos com a aplicação do Caderno Dirigido em sala de aula, considerando que se deveria elaborar um produto educacional provindo de sua prática docente. Este movimento de construção possibilitou a constituição do papel do professor-pesquisador, tal como considera Costa (2015, p. 31):

\begin{abstract}
Quando se pensa em pesquisa na sala de aula, devem ser consideradas a figura do professor e a sua atuação, que pode acontecer em parceria com outros professores em sala de aula ou mediante a investigação da própria prática, isto é, das suas próprias ações nas aulas. Nas duas modalidades, o professor encontra-se continuamente diante de situações desafiadoras e problemáticas, as quais ele procura solucionar com as ferramentas que lhe são acessíveis, muitas vezes alicerçado apenas na experiência profissional, no consenso e na "boa vontade". Entretanto, tal limitação pode ser prejudicial ao seu bom desempenho profissional. Nesse sentido, pensar em novas formas de resolver esses problemas e otimizar a tarefa de ensinar e aprender tornase uma prerrogativa para minimizar a perspectiva nem sempre otimista e tornar 0 processo mais adequado às realizações educacionais.
\end{abstract}

Esse processo de investigação coloca o professor como um indivíduo em constante reflexão sobre os desafios de repensar a própria prática em sala de aula, com a possibilidade de discutir a pesquisa acerca de sua prática docente, em que continuamente irá rever o seu próprio desenvolvimento profissional, a fim de compreender os problemas educacionais que o cercam. 0 crescimento profissional provindo desse tipo de investigação e reflexão da própria prática pode ser melhor configurado, uma vez que

[...] a reflexão relativa à investigação sobre a nossa própria prática não se reduz ao que os académicos podem pensar sobre $o$ trabalho de investigação dos professores. Tem uma outra faceta, tão ou mais importante - a reflexão que os académicos podem e devem fazer sobre a sua própria investigação sobre a sua própria prática, ajudando 
a compreender os problemas que se colocam nos campos de trabalho onde intervêm como profissionais e nas suas instituições. $O$ discurso da investigação sobre a prática não é, por isso, um mero discurso sobre as práticas dos outros, mas é também, e sobretudo, um discurso sobre nós mesmos e a nossa própria prática. (PONTE, 2008, p. 25).

Alguns fatores são importantes para que a atuação do professor-pesquisador seja consistente diante dos objetos de pesquisa, reflexão e análise dentro da realidade da sala de aula. Nesse sentido,

[...] o (a) professor(a) que se dispõe a investigar a própria prática não pode desempenhar essa tarefa de modo solitário. Ele(a) necessita do outro - que podem ser os pares na própria escola, os pares num programa de pós-graduação, o grupo (se ele fizer parte de um), os próprios alunos na sala de aula e, no caso de mestrado, por exemplo, o orientador e os espaços de comunicação e divulgação da pesquisa. (LIMA e NACARATO, 2009, p. 258)

Pode-se ainda afirmar, conforme Bicudo (1992, p. 7), que "[...] quando o professor de matemática interroga o que faz ao estar-com-seus-alunos na sala de aula de matemática e persegue sua interrogação de modo sistemático e rigoroso, está realizando pesquisa".

Diante dessas perspectivas, pode-se identificar a importância do papel do professor pesquisador no processo de investigação sobre a própria prática, em que ele precisa retomar, discutir e repensar a todo momento as suas ações em sala de aula.

Assumindo-se a perspectiva qualitativa de pesquisa, pois há a necessidade de definir 0 que se caracteriza como categorização dos elementos da investigação, tornou-se relevante para que a entrevista fosse analisada, relacionar o discurso pedagógico da obra Didática da Matemática, o discurso oral de Lorenzato com o objeto de estudo Caderno Dirigido, estejam conectados ao processo de aplicação em sala de aula.

Para tanto se tornou necessário definir o processo de categorização, adotando-se a perspectiva de categorias mistas, apontado por Fiorentini e Lorenzato (2006, p. 135) considerando que essas "são dadas quando o pesquisador obtém categorias a partir de um confronto entre 0 que diz a literatura e o que encontra nos registros de campo". No contexto da pesquisa, considerou-se também o registro oral, por meio da entrevista com o educador Sérgio Lorenzato.

O processo de categorização foi organizado a partir de uma leitura criteriosa e cuidadosa da transcrição da entrevista, por diversas vezes, retomando ao depoimento buscando estabelecer relações com o discurso didático de Tahan. Esse exercício de análise permitiu o levantamento de três categorias emergentes mistas: aproximação afetiva e familiarização com a escrita; conversas, valorização da autonomia e criatividade; e escolhas e caminhos a partir dos discursos- do 
depoente ao Malba Tahan. Cada categoria emergente originou-se de fragmentos do depoimento de Lorenzato, tal como apresenta-se a seguir.

\section{Primeira categoria: Aproximação afetiva e familiarização com a escrita}

Esta categoria direcionou o momento da prática docente apresentando aos alunos envolvidos na pesquisa, a perspectiva de valorização da escrita e a aproximação afetiva que 0 professor Lorenzato descreveu ao conviver com Malba Tahan, como mostra o excerto seguinte.

[...] ele foi misterioso e realmente diferenciado, um arauto. Tive a sorte de conhecê-lo e de sentir no final do curso o seguinte: essa Matemática é diferente daquela que me ensinaram e a partir dessa eu quero ser professor. Isso mudou a minha vida. Tinha dois anos de magistério e 22 anos de idade [...] Se eu tivesse tido outros professores na minha formação, professores que acreditassem que além de dar o conhecimento matemático, eles precisariam dar a oportunidade de fazer seus alunos aprenderem a escrever, não fazer cópias do quadro negro, mas aprender a escrever com suas palavras, com seu ritmo, tendo concatenação, um começo, meio e um final, eu teria podido ter produzido muito mais e ter falado muito melhor também [...] Então eu dou graças a Deus por ele (Malba Tahan) ter me pedido para escrever, porque eu comecei através desse caderninho a compreender o quanto é difícil escrever [...] o caderno era algo que ele gostava muito de utilizar, pois essa questão do registro era muito importante para ele [...] Esse caderno não era copiado na aula, você até poderia copiar algo, mas em uma folha qualquer para depois, em casa, passar a limpo isso no caderno, pois era onde a sua criatividade e capricho poderiam estar em destaque maior. Você não precisava abrir comentários. Você precisa mostrar com essas poucas linhas, o que você entendeu para alguém que não assistiu às aulas e isto demanda uma análise e às vezes aquilo ainda era insuficiente e era necessário consultar outros materiais para complementar [...]

(Fragmento 1 - entrevista concedida em 2017)

Entende-se que tais considerações remeteram a um momento inicial de aproximação dialógica e afetiva com a professora pesquisadora — segunda autora deste artigo —, que buscava compreender a importância da construção da escrita para a formação do pensamento matemático.

\section{Segunda categoria: Conversas, valorização da autonomia e criatividade}

No segundo momento situou-se os alunos em um espaço de aprendizagem autônomo e criativo, por meio da escrita do Caderno Dirigido, compreendendo temas discutido nos encontros com a professora-pesquisadora em sala de aula. Apresentou-se a importância da História da Educação Matemática como um subsídio para o processo de construção do cenário para investigação da perspectiva histórica da Matemática, como pode-se identificar no depoimento do professor Sérgio Lorenzato: 
[...] E então ele passava as orientações sobre o que seria feito no Caderno, deixando claro que ali seria feito o registro do que eles estavam fazendo, agora como esse registro seria feito, o aluno teria liberdade total [...] Como ele gostava muito de citar personagens da História da Matemática eu imitei ele, colocando uma frase do Leibniz: "a honra da humanidade é a Matemática" [...] o que eu coloquei aqui na primeira página do meu caderno, foi decisão minha, ele não pediu. Encontrei essa gravura, colei na capa e escrevi uma conversa: "vamos aprender um pouco de Matemática? ", com a assinatura que eu fiz na época [...] O que podemos perceber com isso é que ao fazer esse registro na minha casa, eu estou tendo a autonomia de registrar o que eu estou pensando com relação à Matemática da forma que eu acho melhor e sem perceber estou retomando os conteúdos abordados [...] Ele dedicava parte do tempo dando essa atenção aos alunos. Ele tinha uma maneira muito divertida de conversar com os alunos, fazendo com que a aula passasse sem que percebêssemos [...] ele não era prolixo. Por exemplo o problema do algebrismo, "é a mórbida mania de complicar o ensino da Matemática", então o que quer dizer isto? É tornar pesado o ensino da Matemática o que poderia ser o entulho da Matemática. Era na Álgebra e na Geometria [...]

(Fragmento 2 - Entrevista concedida em 2017)

A partir desse fragmento foi possível orientar o aluno para um momento de reflexão sobre a maneira como ele enxergava a Matemática, além de apresentar a ideia do Geometrismo, criticado por Malba Tahan, buscando exercitar a autonomia e criticidade do aluno acerca do tema e sobre o ensino da Geometria.

Terceira categoria: Escolhas e caminhos a partir dos discursos - do depoente ao Malba $\underline{T a h a n}$

Apresentou-se, aos alunos, o depoimento de Sérgio Lorenzato, a fim não apenas de compreender quais escolhas e caminhos seriam seguidos pelos alunos, a partir do processo inicial de escrita do Caderno Dirigido, mas também com o intuito de conhecer quem foi Malba Tahan e qual mensagem ele pretendia passar naquela época.

[...] Inicialmente eu não estava entendendo qual era a proposta daquele livro, mas na medida que continuei a leitura estava me sentindo imerso a histórias e culturas que eu não conhecia, foi dai que meu interesse aumentou. Entrar nesse universo da cultura árabe, com essas viagens de camelos não fazia parte do que eu já havia visto até então. Fiquei fascinado com os conflitos cognitivos que eu era induzido [...] Ele havia feito escola de dramaturgia (Procópio Ferreira). Essa postura "teatral" era uma marca nas suas aulas onde sempre que possivel havia uma encenação coerente com a sua fala [...] Ele mudou a maneira como eu enxergava a Matemática [...] A realidade é que a Matemática era vista como um castigo [...] Dizia que formular questões tão desconexas com a realidade chegava a ser uma "imbecilidade" [...] Naquele período eles ensinavam de uma maneira muito complicada...Seu objetivo era decorar aquela regra [...] Eu sempre estudei isso como Álgebra e nunca havia feito relação com Geometria naquela época. Hoje nós chamamos isso de Álgebra geométrica, ou seja, a intersecção das duas onde muitos livros didáticos trazem isso, mas não em 1958 [...] Tendo conhecimento você pode fazer escolhas sobre o caminho a seguir [...] Este Caderno desenvolve a sua iniciativa e originalidade assim como você pode verno meu. Você procura coisas e descobre outras coisas e vai desenvolvendo seu caderno estimulando a criatividade [...] Aumenta sim a relação de proximidade entre $o$ aluno $e$ 
o professor porque isso é um elo material. Eu não poderia estar falando aqui com você sobre ele dessa forma se eu não tivesse sentido essa relação afetiva com ele que foi inicialmente visual, mas depois me marcou pela qualidade do trabalho que ele desenvolveu [...]

(Fragmento 3 - Entrevista concedida em 2017)

\section{A escolha de um caderno de classe: o Caderno Dirigido de Malba Tahan}

Foram realizados alguns apontamentos importantes sobre os motivos pelos quais 0 caderno de classe adotado para ser utilizado com os alunos em sala de aula seria o Caderno Dirigido orientado por Júlio Cesar de Mello e Souza.

Malba Tahan descreve características pertinentes ao uso do Caderno Dirigido em sala de aula, pois ele acredita que a partir dessa utilização o professor pode propiciar ao aluno uma perspectiva crítica com relação aos conteúdos matemáticos que são ensinados nas aulas, quando, além da criticidade, o professor pesquisador tem a possibilidade de estabelecer uma relação afetiva e dialógica com 0 aluno.

O caderno de classe elaborado pelo aluno é dia a dia orientado pelo professor, onde o professor lê êsse caderno e nêle assinala elogios, observações e advertências. 0 aluno educa-se e aprende a ter ordem, capricho em seus cálculos e a ser cuidadoso com seus trabalhos. 0 professor transforma o caderno em um recurso de motivação permanente. No caderno de classe do aluno, o estudo abrange os valores utilitários, educativos morais e culturais da matemática [...] onde o professor revela de forma marcante a sua personalidade no ensino. (TAHAN, 1961b, p. 100-101)

Esse olhar trazido por Tahan nos leva a assumir a postura de professor pesquisador diante das responsabilidades com o seu trabalho com a aplicação do Caderno Dirigido em classe, pois ele também destaca a maneira superficial com que eram trabalhados os cadernos de classe naquela época.

Os cadernos criam nos estudantes o vício do estudo superficial e limitado. 0 estudo assim feito irá exercer influência maléfica nos trabalhos posteriores do aluno, principalmente nas profissões que abraçarem. Os alunos que estudam por cadernos sem orientação, além de aprenderem as incongruências que lá estão escritas, o fazem geralmente com o fim exclusivo de tirar uma nota. Copiam e decoram as palavras truncadas do professor e a elas se limitam porque são as que entrarão em exame. , (TAHAN, 1961b, p. 102-103)

Na citação acima, há postura severa e crítica de Malba Tahan com relação ao ensino vigente na época, o qual infelizmente pode-se associar a algumas práticas recorrentes. Há insistência na fala de Tahan sobre a relação cordial, educada e até carinhosa ao lidar com os 
alunos, em que a honestidade e o comprometimento estão acima dos cálculos e das regras matemáticas. De acordo com ele,

o aluno é obrigado ${ }^{2}$ a manter sempre o seu Caderno em dia, isto é, com todos os exercícios marcados. Em caso de irregularidade, atraso ou descontrôle, deverá falar com tôda lealdade ao seu professor, expor as suas dúvidas, as suas dificuldades e pedir auxílio. É do maior interêsse, para o ensino, que o aluno veja no seu professor um guia sereno, um amigo solícito e acolhedor. Se um aluno se atrasar (por qualquer motivo) o professor, sem escândalo, sem ameaçá-lo com punições, deverá ajudá-lo, orientá-lo nos trabalhos e fazer com que êsse aluno fique novamente reajustado à turma. (TAHAN, 1961b, p. 107)

É possível fazer uma associação ao discurso de Tahan presente no livro Didática da Matemática, volume II, com o depoimento do professor Sergio Lorenzato durante a entrevista concedida para a pesquisa.

[...] Malba Tahan era extremamente contundente em as suas falas. Você podia até não concordar, mas ele era realmente muito bem argumentado [...] 0 que o Malba Tahan escreveu sobre vantagens e desvantagens sobre o Caderno eu vejo muito mais como uma estratégia. Apesar desse método ser muito mais trabalhoso para o professor, ele é muito eficiente para mostrar as dificuldades dos alunos, porque se você vai escrever e para que outra pessoa tenha que ler para entender aquilo, você sem dúvidas aumenta a dificuldade [...] Era necessário compreender bem o que era, para que assim pudesse ensinar. Quem não sabe, não entendeu não consegue ensinar [...] Em 1958 para mim, foi algo escandaloso. Posso dizer que o curso dele me surpreendeu profundamente [...]

(Fragmento 4 - Entrevista concedida em 2017)

Pode-se justificar a importância da utilização desse caderno de classe, segundo a fala de Tahan (1961b, p. 108):

É de todo interêsse que o professor esclareça os seus alunos sôbre a importância do Caderno de Classe. Com efeito. Êsse caderno não será um simples caderno de apontamentos, ou de exercícios, - como era de praxe no ensino tradicional, rotineiro ou clássico. 0 Caderno de Classe é um verdadeiro trabalho dirigido, no qual o aluno pratica várias atividades relacionadas com aprendizagem moderna da Matemática. 0 Caderno de Classe será, portanto, uma espécie de livro-auxiliar, complemento do livrotexto, que o aluno organiza, dia a dia, orientado pelo professor, mas ao qual cada aluno imprime um cunho pessoal.

Diante desses discursos, tornaram-se consolidadas as perspectivas de utilização do Caderno Dirigido como um instrumento para ser utilizado em sala de aula, pois a partir dele podese propiciar, entre educador e educando, uma relação crítica, reflexiva, afetiva e dialógica.

\footnotetext{
${ }^{2}$ No texto, foi utilizado o termo "orientado".
} 


\title{
50 discurso pedagógico de Malba Tahan no contexto da pesquisa
}

Foi possível identificar uma relação do discurso de Tahan, presente na obra Didática da Matemática, volume II, com a entrevista de Sérgio Lorenzato, realizada em 2017.

\begin{abstract}
[...] Malba Tahan era extremamente contundente em as suas falas. Você podia até não concordar, mas ele era realmente muito bem argumentado [...] 0 que o Malba Tahan escreveu sobre vantagens e desvantagens sobre o caderno eu vejo muito mais como uma estratégia. Apesar desse método ser muito mais trabalhoso para o professor, ele é muito eficiente para mostrar as dificuldades dos alunos, porque se você vai escrever e para que outra pessoa tenha que ler para entender aquilo, você sem dúvidas aumenta a dificuldade [...] Era necessário compreender bem o que era, para que assim pudesse ensinar. Quem não sabe, não entendeu não consegue ensinar [...] Em 1958 para mim, foi algo escandaloso. Posso dizer que o curso dele me surpreendeu profundamente $[. .$.
\end{abstract}

(Fragmento 5 - Entrevista concedida em 2017)

Ao justificar a importância da utilização do caderno de classe, Tahan (1961b, p. 108) considerou ser

\begin{abstract}
de todo interêsse que o professor esclareça os seus alunos sôbre a importância do Caderno de Classe. Com efeito. Êsse caderno não será um simples caderno de apontamentos, ou de exercícios, - como era de praxe no ensino tradicional, rotineiro ou clássico. O Caderno de Classe é um verdadeiro trabalho dirigido, no qual o aluno pratica várias atividades relacionadas com aprendizagem moderna da Matemática. 0 Caderno de Classe será, portanto, uma espécie de livro-auxiliar, complemento do livrotexto, que o aluno organiza, dia a dia, orientado pelo professor, mas ao qual cada aluno imprime um cunho pessoal.
\end{abstract}

Ao relacionar tais discursos, tomou-se como possibilidade a utilização do Caderno Dirigido como um instrumento pedagógico para ser utilizado em sala de aula, acreditando-se que poderia propiciar uma relação crítica, reflexiva, afetiva e dialógica entre educador e educando. $\mathrm{Na}$ entrevista concedida pelo professor Sergio Lorenzato, destacou-se ainda características do estudo dirigido apontadas no curso realizado por ele em São Carlos.

O livro Didática da Matemática II, de Tahan, descreve o estudo dirigido como sendo

\begin{abstract}
a conceituação, clara e precisa, da atividade escolar, que denominamos estudo dirigido, é problema que avulta, entre muitos outros, no campo da Didática. Ao primeiro e rápido exame, somos forçados a concluir o seguinte: três conceitos, todos de natureza complexa, apresentam-se implícitos no conceito de estudo dirigido: 1) conceito de ensino; 2) conceito de estudo e 3) conceito de aprendizagem. (TAHAN, 1961b, p. 23)
\end{abstract}

Destacou-se algumas características relevantes sobre o estudo dirigido na leitura minuciosa da obra, sugerindo aspectos interessantes ao aluno, como propiciar o trabalho mental, a reflexão e o senso crítico estimulando a sua autonomia. Pode-se verificar uma turma que segue 
orientação de estudos de forma autônoma individual e em grupo, cujos principais objetivos são: 1) a orientação de estudos da turma; 2) a correção dos pontos fracos e deficientes da aprendizagem; 3) a aprendizagem; e 4) o estímulo a uma ação colaborativa do aluno em sala de aula.

Outro fator considerado foi o que Tahan destacou como sendo a maior preocupação do professor: motivar os seus alunos.

A preocupação máxima do bom professor é motivar os seus alunos, isto é, levá-los: 1) a acompanhar, com entusiasmo, os trabalhos; 2 ) a ouvir, com simpatia, as preleções; 3) a cooperar com os colegas; 4) a resolver, com interesse e prazer, os problemas e exercícios; 5) a estudar com boa técnica; 6) a ser correto, caprichoso e leal; 7) a apreciar, com encantamento, até mesmo as divagações sobre teorias e pesquisas abstratas; 8) a fixar as noções aprendidas; 9) a adquirir gosto pelos estudos e pelas pesquisas matemáticas. Para atingir tais objetivos o professor é levado a adotar nas suas aulas, sistemas e artifícios que tornem mais vivo e mais interessante o ensino. Recorre, desse modo, ao ecletismo: torna-se, como já dissemos, eclético. (TAHAH, 1961b, p. 88)

Ao longo do processo de aproximação com a história de Malba Tahan e com seu discurso pedagógico por meio da obra Didática da Matemática, unindo ao privilégio de entrevistar 0 educador matemático, ex-aluno de Tahan, ouvir suas considerações e experiências vivenciadas, elaborou-se o produto educacional Caderno Dirigido com os alunos envolvidos na pesquisa.

O Caderno Dirigido revelou a criatividade na escrita e os elementos presentes nas categorias oriundas da entrevista concedida por Lorenzato, finalizando os encontros com a apresentação de uma peça teatral sobre Malba Tahan, unindo os temas biografia, História da Matemática e ensino, ensino de Geometria e Geometrismo, trabalhados nos encontros e registrados no Caderno Dirigido individualmente.

O Caderno Dirigido foi utilizado no projeto com algumas adaptações, preservando 0 principal objetivo do instrumento, "dar voz aos alunos", a fim de protagonizarem o processo de criação das cenas para a investigação matemática.

Buscou-se, ainda, com o projeto e, especificamente com a entrevista que privilegiou 0 discurso oral, contribuir para reflexões acerca da prática docente no sentido de o professor pesquisador reconhecer sua prática em sala de aula, privilegiando um processo contínuo de conhecimento e de autocrítica. 


\section{Referências}

ABREU, Rodrigo. Guimarães. Uma história oral da Etnomatemática: caminhos para a dimensão educacional. 2017. 195f. Dissertação (Mestrado em Educação) - Faculdade de Educação. Universidade São Paulo. São Paulo.

AMADO, Jorge. Manual de investigação qualitativa em Educação. Coimbra: Imprensa da Universidade de Coimbra, 2013.

BICUDO, Maria Aparecida Viggiani. Relação entre a pesquisa em Educação Matemática e a prática pedagógica. Bolema, Rio Claro, v. 7, n. 8, p. 7-14, 1992.

COSTA, Leonardo Santos. Malba Tahan e a revista Al-Karismi: diálogos e possibilidades interdisciplinares com a História da Educação Matemática no Ensino Fundamental. 2015. $112 f$. Dissertação (Mestrado em Ensino de Ciências e Matemática) - Instituto de Ciências Exatas e Naturais do Pontal. Universidade Federal de Uberlândia. Ituiutaba.

FIORENTINI, Dario; LORENZATO, Sergio. Investigação em Educação Matemática: percursos teóricos e metodológicos. Campinas: Autores Associados, 2006.

GARNICA, Antonio Vicente Marafioti; SOUZA, Luzia Aparecida de. Elementos de História da Educação Matemática. São Paulo: Cultura Acadêmica, 2012.

LIMA, Claudia Neves do Monte Freitas; NACARATO, Adair Mendes. A investigação da própria prática: mobilização e apropriação de saberes profissionais em Matemática. Educação em Revista, Belo Horizonte, v. 25, n. 2, p. 241-266, ago. 2009.

OLIVEIRA, Cristiane Coppe de. Do menino "Julinho" a "Malba Tahan": uma viagem pelo oásis do ensino da Matemática. 2001. 192f. Dissertação (Mestrado em Educação Matemática) - Instituto de Geociências e Ciências Exatas. Universidade Estadual Paulista. Rio Claro.

PONTE, João Pedro da. Investigar a nossa própria prática: uma estratégia de formação e de construção do conhecimento profissional. Revista de Investigación en Didáctica de la Matemática, Granada, v. 2, n. 4, p. 153-180, jun. 2008.

TAHAN, Malba. Didática da Matemática. v. 1. São Paulo: Saraiva, 1961a.

TAHAN, Malba. Didática da Matemática. v. 2. São Paulo: Saraiva, 1961b. 